\title{
Mutations in the Caenorhabditis elegans Na,K-ATPase $\alpha$-Subunit Gene, eat-6, Disrupt Excitable Cell Function
}

\author{
M. Wayne Davis, ${ }^{1}$ Delores Somerville, ${ }^{2}$ Raymond Y. N. Lee, ${ }^{1}$ Shawn Lockery, ${ }^{3}$ Leon Avery, ${ }^{1}$ and Douglas M. \\ Fambrough $^{2}$ \\ 'Department of Biochemistry, University of Texas Southwestern Medical Center, Dallas, Texas 75235-9038, \\ 2Department of Biology, The Johns Hopkins University, Baltimore, Maryland 21218, and ${ }^{3}$ Institute of Neuroscience, \\ 1254 University of Oregon, Eugene, Oregon 97403-1254
}

\begin{abstract}
We have cloned a $\mathrm{Na}, \mathrm{K}$-ATPase $\alpha$-subunit gene from Caenorhabditis elegans and discovered that it is identical to the gene eat-6. eat -6 mutations cause feeble contractions and slow, delayed relaxations of pharyngeal muscle. The resting membrane potential of eat-6 mutant pharynxes is consistently depolarized compared to wild-type. The action potentials are smaller, and the return to resting potential is slower. To explain these abnormalities, we propose that a reduction of $\mathrm{Na}, \mathrm{K}-\mathrm{ATP}$ ase activity in eat- 6 mutants leads to a reduction of the ion concentration gradients that power membrane potential changes.
\end{abstract}

[Key words: $\mathrm{Na}, \mathrm{K}$-ATPase, genetics, Caenorhabditis elegans, ouabain, pharynx, negative spike channel]

Excitable cells must maintain ionic gradients across their plasma membranes in order to function properly. Genetics has been an important tool for getting to the molecular basis of excitable cell functions and for establishing correlations between cellular function and organismic function. For example, the Drosophila genes Shaker, ether-a-go-go, and slowpoke encode ion channel subunits (Tempel et al., 1987; Atkinson et al., 1991; Warmke et al., 1991). Likewise, "bang-sensitive" phenotypes in Drosophila have been shown to be caused by mutations in a Na,K-ATPase (sodium pump) $\alpha$-subunit gene (Schubiger et al., 1994), and the gene encoding ethanolamine kinase, an enzyme necessary for the synthesis of membrane phospholipids (Pavidis et al. 1994).

Several features make the $C$. elegans pharynx a favorable genetic model for excitable cell function and behavior. First, the pharynx is a simple, almost self-contained neuromuscular pump containing 62 cells whose anatomy is known (Albertson and

\footnotetext{
Received Apr. 19, 1995; revised Aug. 24, 1995; accepted Aug. 29, 1995.

We thank Dr. Kunio Takeyasu, Ohio State University Biotechnology Center, for his participation in the initial genomic library screening; Dr. Andrew Fire, Carnegie Institution of Washington, for the gift of the lambda-ZAP cDNA library, for his help in analysis of trans-splicing, and for his advice throughout the project; Dr. Robert Barstead and Dr. Marty Chalfie for gifts of other cDNA libraries; Dr. Alan Coulson and the staff of the MRC-LMB, Cambridge, England, for determining the map position of the $\mathrm{Na}, \mathrm{K}$-ATPase genomic clone; and Simon Tuck for sharing strains and genetic mapping information. We thank David Raizen, Joseph Dent, Flora Katz, and James Thomas for comments on the manuscript. This material is based upon work supported under a National Science Foundation Graduate Research Fellowship to M.W.D. This work was supported by Research Grants HL46154 to L.A. and NS23241 to D.M.F. from the National Institutes of Health of the United States Public Health Service and by Research Grant 9311453 to S.L. from the National Science Foundation.

Correspoondence should be addressed to Wayne Davis, Department of Biochemistry, University of Texas Southwestern Medical Center, 5323 Harry Hines Boulevard, Dallas, TX 75235-9038.

Copyright (C) 1995 Society for Neuroscience $0270-6474 / 95 / 158408-11 \$ 05.00 / 0$
}

Thomson, 1976). Second, the role of the pharyngeal nervous system in controlling pharyngeal behavior can be investigated by killing any of the 20 pharyngeal neurons with a laser microbeam, either individually or in combinations. In this way, it has been shown that only one of the pharyngeal neurons is necessary for viability (Avery and Horvitz, 1987), and that pharyngeal pumping continues in the absence of all 20 pharyngeal neurons (Avery and Horvitz, 1989). Third, the C. elegans pharynx is well suited to genetic analysis. Because the function of the phar$y n x$ is to ingest and grind food, mutations that affect pharyngeal function cause worms to have a characteristic starved appearance. $\Lambda$ subsaturation screen for mutations affecting feeding behavior identified 52 mutations in 35 genes (Avery, 1993a). These mutations caused defects in pharyngeal muscle structure, nervous system function, and muscle excitability-indicating that many aspects of pharyngeal function are open to genetic dissection. Fourth, a simple method for measuring pharyngeal muscle action potentials in living worms has been developed by Raizen and Avery (1994). This technique, called the electropharyngeogram (EPG), involves sucking the mouth of a worm into a pipette and recording the currents that flow in and out of the mouth due to changes in the potential across the basal membranes of the pharyngeal muscles. These currents derive from two sources: pharyngeal muscle action potentials, and postsynaptic potentials caused by synaptic transmission from the pharyngeal nervous system onto the pharyngeal muscle. EPGs can show the effects of mutations, neuron ablations and drugs on the electrical activity of the pharyngeal muscles.

Three eat-6 alleles, ad467, ad601, and ad792, were previously isolated in screens for feeding-defective worms (Avery, 1993a). All three mutations are recessive and cause slow, delayed pharyngeal relaxation (Avery, 1993a). Because this phenotype had never been seen when subsets of the pharyngeal nervous system were killed, eat- 6 was proposed to be involved in controlling pharyngeal muscle excitability (Avcry, 1993a). In this article we show that eat- 6 encodes the $\alpha$ subunit of a $C$. elegans $\mathrm{Na}, \mathrm{K}$-ATPase. We also demonstrate that eat- 6 mutant worms have defects in their pharyngeal muscle membrane potential which lead to defects in pharyngeal contraction and relaxation behavior.

\section{Materials and Methods}

General methods and strains. Worms were cultured and handled as described by Sulston and Hogkin (1988) with minor modifications as described by Avery (1993a) and were grown at $20^{\circ} \mathrm{C}$. The wild-type was C. elegans variety Bristol, strain N2. Mutant strains used were CB 1072 unc-29(e1072) I, DA467 eat-6(ad467) V, DA601 eat-6(ad60I) V, DA690 him-8(e1489) IV; eat-6(ad467) V, DA709 sqt-3(sc63) eat-6(ad467) unc- 
$76(e 911)$ V/ nTl(V), DA792 eat-б(ad792) V, DA793 unc-29(e1072um) $I$; eat-6(ad467) V, DA842 unc-29(e1072am) I; eat-6(ad792cs) V, DA843 unc-29(e1072am) I; eat-6(ad601) V, DA898 unc-29(e1072am) I; sntI(md290) II, DA932 unc-29(el0/2am) l; snt-l(ad596) Il, DA99' eat6(ad997) V, GS357 +/nTl(let (-) unc $(n 754 s d)) ;$ unc-42(e270) arDfl $V / n T l(V)$, GS856 rol-4(sc8) lin-25(n545ts) him-5(e1467ts) V. eat6(ad997) was isolated in a screen among the viable $\mathrm{F} 2$ progeny of mutagenized hermaphrodites for worms that had abnormal electrical signals (Joseph Dent, personal communication). unc-29(e1072) is described by Brenner (1974). snt-I(ad596), previously named ric-2 (Avery, 1993a), is a partial loss-of-function mutationin the synaptotagmin gene snt- 1 (Nonet ct al, 1993; data not shown). Other mutations are described by Avery (1993a).

Two E. coli strains were used, DA837 and HB101 (Boyer and Roulland-Dussoix, 1969). DA837 was derived from OP50 (Brenner, 1974) as follows. First, a spontaneous streptomycin-resistant mutant was selected (S Kim, personal communication). When spread on NGMSR (Avery, 1993a), this strain produced a thin lawn with faster-growing papillae. One of these papillae was streaked out and a single colony isolated. This strain, which produced uniform thick lawns without papillae, was serially passaged on NGMSR for about a year. Finally, a single colony was isolated and frozen. This is DA837.

When grown on NGMSR, E. coli HB101 bacteria do not adhere to each other. Consequently they produce a low-viscosity lawn that is easy for worms to eat. DA837 bacteria adhere when grown on NGMSR and produce a viscous, gumny lawil that is more difficult to eat. This has little effect on wild-type worms or on mutants such as unc-29(el072) that feed normally, but can make a drastic difference in the growth rate of feeding-defective worms. eat-6 mutants were routinely grown on HB 101. Growth rates of transgenic worms and progeny production rates of eat- 6 mutants were assayed on DA837 because it makes the difference between mutant and wild-type more obvious.

DNA manipulations. A genomic DNA clone encoding a Na,K-ATPase $\alpha$-subunit was obtained by screening a $C$. elegans genomic DNA library in $\lambda$ EMBL4 at low stringency with a cDNA probe encoding the chicken Na,K-ATPase $\alpha 1$-subunit. A cDNA clone encoding part of the $C$. elegans Na,K-ATPase $\alpha$-subunit was subsequently obtained by probing a $\lambda$-ZAP (Stratagene, La Jolla, CA) cDNA library at high stringency with a DNA fragment from the $C$. elegans genomic clone. Both genomic and cDNA clones were digested with HindIII and EcoRI, and restriction fragments were subcloned into the plasmids pEMBL18 and pBluescript. Nucleotide sequence analysis was performed by the dideoxy chain termination method (Sanger and Coulson, 1975). The sequence was determined for both DNA strands. For some coding segments, the nucleotide sequence of one strand was determined from genomic DNA and the other from cDNA. The complete sequence has been deposited in the Genbank data base, accession number U18546.

$\Lambda$ lambda phage clone covering the $e a t-6(+)$ gene, $\lambda 2.4$, was isolated by screening a $C$. elegans genomic library (Stratagene, La Jolla, CA) with digoxigenin-labeled (Genius kit, Boehringer-Manheim, Indianapolis, IN) probes from an EcoRI subclone of the $\mathrm{Na}, \mathrm{K}^{\prime}$-ATPase genomic region. A HindIII to BamHI restriction fragment containing the $5^{\prime}$ end of the reported sequence and a BamHI to SacI subclone containing the $3^{\prime}$ end of the reported sequence plus $1 \mathrm{~kb}$ of downstream genomic sequence were subcloned into pBluescript. These subclones were joined in a pBluescript vector to form pE6HinSac.

Trans-splicing analysis. Reverse transcriptase/polymerase chain reaction (RT/PCR) was used to amplify the sequence corresponding to the $5^{\prime}$ end of the $\mathrm{Na}, \mathrm{K}$-ATPase $\alpha$-subunit mRNA. As $5^{\prime}$ primer, the synthetic oligonucleotide 5'-GGAATTCGGTTTAATTACCCAAGT-3' was used. This primer contains an EcoRI site at the $5^{\prime}$ end for cloning and a 17-base sequence that corresponds to the trans-splice $5^{\prime}$ end of splice leader 1 (Krause and Hirsh, 1987). As $3^{\prime}$ primer, an 18-mer of sequence $5^{\prime}$-caacaagctcctcaatcG-3' was used, corresponding to the antisense of nucleotides $75-92$ in the coding region, where the first A of the start codon is numbered 1 . The PCR product was cloned and sequenced.

Transformation rescue. pRAK 3 was generated by the insertion of the kanamycin resistance gene from Tn5 into pRF4 $[$ rol- $6(d)]$ and was used as a coinjection marker (Kramer et al., 1990). eat-6(ad792) hermaphrodites grown at $25^{\circ} \mathrm{C}$ were transformed with a mixture of pRAK3 and cosmid R07B8 or pE6HinSac by the method of Mello et al. (1991). The transformed F1 progeny were scored for rescue of the visible cat 6 pumping defect, and stably transmitting Rol lines were scored for rescue of the visible pumping defect and of growth at $15^{\circ} \mathrm{C}$. eat-6(ad467)
Table 1. EPG phenotype of eat-6 alleles

\begin{tabular}{lll} 
Genotype & $\begin{array}{l}\text { \% pumps } \\
\text { R Spike height } \\
\text { with REM (pA) } \\
\text { spikes } \\
<20 \mathrm{pA}\end{array}$ \\
\hline Wild-type & $397 \pm 37$ & 0 \\
eat-6 (ad601) & $263 \pm 7^{* *}$ & 0 \\
eat-6 (ad792) & $198 \pm 27^{*}$ & 9 \\
eat-6 (ad997) & $188 \pm 27^{* *}$ & 3 \\
eat-6 (ad467) & $182 \pm 31^{* *}$ & 20 \\
eat-6 (ad467) + w.t. transgene & $325 \pm 33 \dagger$ & 0 \\
Wild-type 15 & $273 \pm 24$ & 0 \\
eat-6 (ad792) $15^{\circ}$ & $109 \pm 25 \ddagger$ & 19
\end{tabular}

Data are R-spike heights of wild type and eat-6 alleles. Each height is the average of the average spike height during a $5 \mathrm{~min} E P G$ recording from each of five worms. The percentage of pumps with $R$ spikes less than $20 \mathrm{pA}$ is the total number of pumps that meet this criterion divided by the total number of pumps for all five worms. ${ }^{*}, P<0.05 ; * *, P<0.01$ different from wild-type; †. $P<0.05$ different from ad467; $\neq, P<0.05$ different from wild-type $15^{\circ} \mathrm{C}$.

worms stably transformed with pRAK3 and pE6HinSac were scored for rescue of the visible pumping defect and the electropharyngeogram defect.

Genetic mapping. By three point mapping, eat-6 maps to the right of the cloned gene lin-25 (12/19 Sqt $\mathrm{Eat}^{+} \mathrm{Unc}^{+}$recombinants from a sat-3 eat-6 unc-76/rol-4 lin-25 him-5 heterozygote carried lin-25 and a single Sqt ${ }^{+}$Eat Unc recombinant didn't carry lin-25). We placed eat-6 to the left of the polymorphism arP3 because the deletion arDfl, which does not delete the polymorphism (Simon Tuck, personal communication), fails to complement both eat-6 and lin-25 (see Fig. 3). We previously reported three-point mapping results that placed eat-6 left of egl-10, a position inconsistent with the new data. The previous error was probably caused either by incorrect scoring of egl-10, or by reversion of the egl-10 mutation in the strain used.

Extracellular recordings (EPGs). Extracellular recordings were made using methods based on those of Raizen and Avery (1994). Adult hermaphrodites were transferred into an approximately $1 \mathrm{~cm}$ diameter drop of Dent's saline solution on a $35 \times 50 \mathrm{~mm}$ glass coverslip (Carolina Biological). Dent's saline (Avery et al., 1995) is $140 \mathrm{~mm} \mathrm{NaCl}, 6 \mathrm{~mm}$ $\mathrm{KCl}, 3 \mathrm{mM} \mathrm{CaCl}_{2}, 1 \mathrm{~mm} \mathrm{MgCl}$, and $5 \mathrm{~mm}$ Hepes (pH 7.4). In addition to these components, the bath containcd $10 \mathrm{~mm} 5-\mathrm{HT}$ to stimulatc pumping as indicated in figure legends (Horvitz et al., 1982; Avery and Horvitz, 1990). Except when otherwise indicated, recordings were done at ambient temperature $\left(21-26^{\circ} \mathrm{C}\right)$. Recordings were made at $15^{\circ} \mathrm{C}$ by placing a $100 \mathrm{ml}$ beaker of dry ice+ethanol on the edge of the microscope stage. This arrangement was empirically determined to give a bath temperature of $15 \pm 1.5^{\circ} \mathrm{C}$ measured in a simmilar bath under simmilar conditions before recording. Electrophysiological preparations were watched with a Zeiss Axiovert inverted microscope equipped with Nomarski differential interference contrast optics. Statistical comparisons between R-spike heights were made using the exact $U$ test (Avery, 1993a).

Current measurements were done with an Axopatch-1D amplifier from Axon Instruments (Foster City, CA) in voltage-clamp mode, which gives reproducable spike amplidudes (Raizen and Avery, 1994). The data were low pass filtered at $1 \mathrm{kHz}$ using a 4-pole Bessel filter in the amplifier. The electrical signal from the amplifier was sampled and recorded using an AT-MIO-16 ADC board from National Instruments (Austin, TX) and software we wrote in the Labview software development environment from National Instruments. The sampling rate was $2 \mathrm{kHz}$. Further filtering and analysis were done on a Sun Microsystems SPARCstation 2 running the MIT Xwindow system and software we wrote (Raizen and Avery, 1994). Data in Figures 4 and 7 were digitally filtered by convolution with a gaussian of width $\sigma=0.5 \mathrm{msec}$. R-Phase spikes were identified as a drop of at least $20 \mathrm{pA}$ within $15 \mathrm{msec}$, followed by a rise of at least $20 \mathrm{pA}$ within $15 \mathrm{msec}$. Spike heights were measured as the average of the maximum (i.e., most positive) current values within $15 \mathrm{msec}$ on each side of the spike minus the minimum (i.e., most negative) current at the peak of the spike. Pumps with R-phase spikes less than $20 \mathrm{pA}$ were identified visually and were counted as $20 \mathrm{pA}$ spikes for statistical purposes in Table 1 . 
Intracellular recording. We dissected pharynxes out of adult hermaphrodites in Dent's saline as described below for ouabain pharmacology. Pharynxes were held in place with a pipette of approximately $30 \mu \mathrm{m}$ tip diameter held in a pipette holder (World Precision Instruments, Sarasota, FL) coupled to a suction syringe similar to the design of Delcomyn (1974). All manipulations were done with Narishige 3-D hydraulic joystick micromanipulators mounted on a Zeiss Axiovert inverted microscope equipped with Nomarski differential interference contrast optics.

Intracellular electrodes were pulled on a P-87 puller from Sutter Instruments (Novato, CA). These electrodes were filled with $500 \mathrm{~mm}$ potassium acetate and had a resistance of 100-400 M $\Omega$. Membrane potentials were measured with the bridge mode of an Axon Instruments (Foster City, CA) Axoclamp 2B with an HS-2A $0.1 \times \mathrm{L}$ headstage. Recordings were made from terminal bulb muscles. Preparations that did not pump after electrode insertion were discarded. Analog signals were recorded and analyzed as for extracellular recording. Records in Figure 5 were digitally filtered by convolution with a gaussian of width $\sigma=0.5 \mathrm{msec}$.

Resting membrane potentials were obtained from 4 min records which began approximately $4 \mathrm{~min}$ after penetrating the muscle. The average resting potential was calculated by visually marking quiescent regions between action potentials and calculating the average voltage in these regions using software written in the Labview software development environment from National Instruments. The pipette offset measured after withdrawal of the electrode was subtracted from this value to give the true average resting potential. Only records that returned to within $\pm 5 \mathrm{mV}$ of the bath potential after withdrawal of the electrode were considered to accurately represent the true membrane potential. Action potential peak and overshoot values were obtained using the peak detection software described above to find peak and trough values. The peak and overshoot values for a record were averaged and the pipette offset value was subtracted from these values to give the true average action potential peak and overshoot value. Statistical comparisons were made with the exact $U$ test (Avery, 1993a) and variances were compared using an $F$ test (Sokal, 1981).

Muscle isolation experiments. Pharyngeal muscle was isolated from other tissues by laser-killing all pharyngeal neurons except M4, then dissecting the pharynx away from the rest of the worm. Laser-killing was done as described by Avery and Horvitz (1987) and Avery (1993b). Dissection is described below under ouabain pharmacology. All worms carried unc-29(e1072) to minimize escape to the edges of the plate (Avery and Horvitz, 1987). Operated unc-29; eat-6 and unc-29; snt-1 worms were grown on HB101. In some cases the plate was flooded with $1 \mathrm{ml}$ mineral oil to minimize drying of the plate, which tended to reduce growth and viability. Some operated unc-29; eat- $6(+)$ worms were grown partly on DA837 in order to starve them so they would be morc directly comparable to the mutants.

On the day it became a fertile adult a worm was transferred to a bath of either Ascaris saline (Raizen and Avery, 1994) + $10 \mathrm{~mm}$ 5-HT or Dent's saline $+10 \mathrm{mM} 5-\mathrm{HT}$, and an EPG and simultaneous video (Raizen and Avery, 1994) were recorded for ten minutes. After the recording we put the worm back on a petri plate for at least $10 \mathrm{~min}$. Dissection was then attempted. If successful, we recorded an EPG and video for $10 \mathrm{~min}$. A dissection was considered successful if the terminal bulb was exposed, and if there was no obvious damage before or after recording. Finally, the pharynx was ejected from the suction pipette and examined for tetanus, defined as a full contraction of corpus, isthmus, and terminal bulb muscles lasting several seconds or more. [Wild-type contractions never last longer than a second, and are typically 150-200 msec long (Avery, 1993a,b). Some eat-6 pharynxes showed obvious tetanus only after ejection, perhaps because the suction, working against the contraction, prevented the pharynx from opening fully.]

M4 kills. M4 kills were done in unc-29 mutant backgrounds, and the worms grown on HB101. As reported in Results, a few eat-6(+) worms grew and were fertile, in contrast to previous experiments where M4 was essential (Avery and Horvitz, 1987). In the previous experiments the worms were grown on $E$. coli OP50, which, like DA837 (a derivative of OP50), produces a viscous gummy lawn that is more difficult for worms to eat. Consistent with the earlier results, M4 is essential on DA837: 0/23 produced progeny within $21 \mathrm{~d}$.

Progeny production rate. Stocks of each genotype were grown at $20^{\circ} \mathrm{C}$ on plates seeded with $E$. coli IIB 101 . Gravid adult hermaphrodites were then transferred to plates seeded with E. coli DA837 and placed at $15^{\circ} \mathrm{C}, 20^{\circ} \mathrm{C}$, or $25^{\circ} \mathrm{C} 14 \mathrm{hr}$ before rate measurements began. Because these results were comparable to the results obtained when DA467 and DA792 worms were transferred to $15^{\circ} \mathrm{C}, 20^{\circ} \mathrm{C}$, or $25^{\circ} \mathrm{C}$ several days before rate measurements began, $14 \mathrm{hr}$ is long enough to adapt the worms to the test conditions (data not shown). For each genotype, three worms were transferred to each of five DA837 seeded plates (i.e., 15 worms/genotype), and these plates were placed at the test temperature for $9 \mathrm{hr}$. At the end of this time the adult worms were removed from the plates, and the plates were placed at $20^{\circ} \mathrm{C}$. The number of progeny on each plate were counted after $2 \mathrm{~d}$ for wild-type, $3 \mathrm{~d}$ for $\mathrm{D} \Lambda 601$ and DA997, and $4 \mathrm{~d}$ for DA467 and DA792. For DA601, 1 plate from $15^{\circ} \mathrm{C}$, 1 plate from $20^{\circ} \mathrm{C}$, and 1 plate from $25^{\circ} \mathrm{C}$ were discarded because one of the progeny on those plates began to lay eggs. For DA467, three plates from $15^{\circ} \mathrm{C}$ were discarded because one of the parent worms became stuck to the side of the plate.

Ouabain phenocopy and sensitivity measurements. For experiments involving ouabain application pharynxes were first dissected into a saline bath where the drug could access the muscles directly, without having to penetrate the cuticle (Avery et al., 1995). The worm was placed in Dent's saline $+1 \mu \mathrm{M}$ 5-HT and cut through just behind the terminal bulb with a \#11 surgical blade. Successful dissections removed the intestine from the pharynx and exposed all of the terminal bulb and most of the isthmus. Pharynxes were allowed to recover for $2-5 \mathrm{~min}$ after dissection. A suction electrode was placed on the mouth as for intact worms and extracellular recordings were made and analyzed as described above. Pumping and EPG recordings made from dissected pharynxes look similar to recordings made from intact worms (unpublished observations). Pharynxes with abnormal EPGs or eat-6(ad601) pharynxes with R-phase spikes consistently below $100 \mathrm{pA}$ were discarded. Prior to drug application, a 1-10 min recording was made. The drug was applied by adding an equal volume of ouabain (Sigma, St. Louis, MO) of double the desired final concentration in Dent's saline to the bath. The bath was then gently mixed by repeated pipetting. After $5 \mathrm{~min}$ of exposure to drug, we recorded for $1 \mathrm{~min}$. Washout was accomplished by exchanging the bath solution with fresh saline at least five times and waiting $5 \mathrm{~min}$. Two out of 7 wild-type worms that were exposed to $20 \mu \mathrm{M}$ ouabain hypercontracted and produced no $\mathrm{R}$ spikes. Becuse spikes less than $20 \mathrm{pA}$ were not counted, these worms were not included in the average $\mathrm{R}$ spike heights in Figure $7 b$. Quantification was done using the software described above. R-phase spikes were identified as a drop of at least $20 \mathrm{pA}$ within $15 \mathrm{msec}$, followed by a rise of at least $20 \mathrm{pA}$ within $15 \mathrm{msec}$. Spike heights were measured as the average of the maximum (i.e., most positive) current values within 15 msec on each side of the spike minus the minimum (i.e., most negative) current at the peak of the spike.

\section{Results}

\section{Characterization of a Na,K-ATPase $\alpha$-subunit gene}

The nucleotide sequence of the $\mathrm{Na}, \mathrm{K}$-ATPase $\alpha$-subunit gene is presented in Figure 1, with coding sequence in capital letters. There is a splice acceptor consensus sequence TTTACAG, beginning 15 bases upstream of the start codon, that is involved in trans-splicing of the mRNA (Materials and Methods). The coding sequence is interrupted by four introns of $190,49,52$, and 57 bases, highlighted in Figure 1. Each intron begins with a consensus splice donor sequence GTAAG or GCAAG and each ends with a splice acceptor sequence TTTCAG.

The deduced amino acid sequence of the $C$. elegans $\mathrm{Na}, \mathrm{K}$ ATPase $\alpha$-subunit is shown in Figure 2, aligned with sequences from the Drosophila Na,K-ATPase $\alpha$-subunit (Lebovitz et al., 1989), and the chicken (Takeyasu et al., 1988) and rat (Shull et al., 1986) Na,K-ATPase $\alpha 1$-subunits. The 10 putative transmembrane spans $(\mathrm{H} 1-\mathrm{H} 10)$ are underlined in the figure, and the phosphorylation site and FITC-reactive site are indicated. There is $72 \%$ amino acid sequence identity between the $C$ elegans sequence and each of the other $\mathrm{Na}, \mathrm{K}$-ATPase $\alpha$-subunit sequences. In contrast there is only $52 \%$ identity with a mammalian $\mathrm{H}, \mathrm{K}$ ATPase $\alpha$-subunit (Maeda et al, 1988). We conclude that the nucleotide sequence encodes a Na,K-ATPase $\alpha$-subunit. 


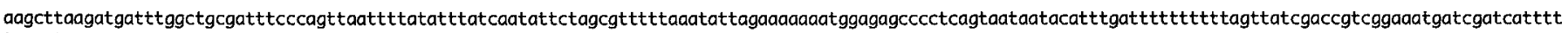

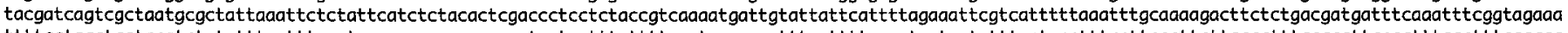

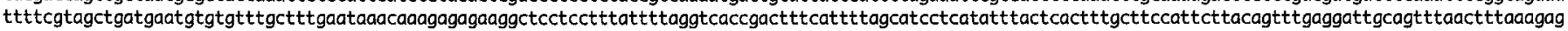

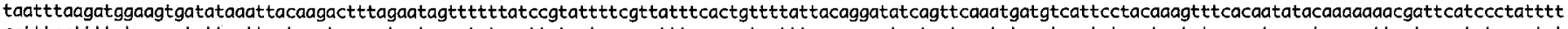

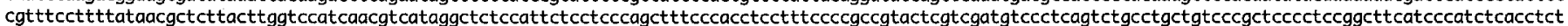

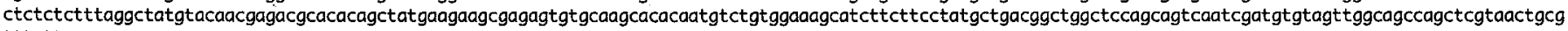

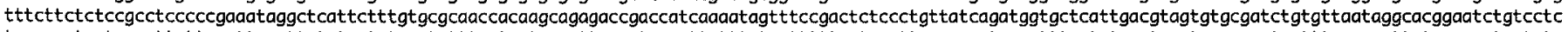

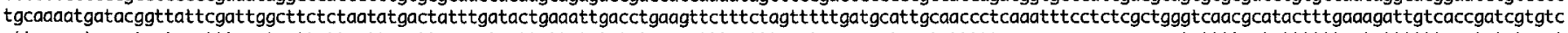

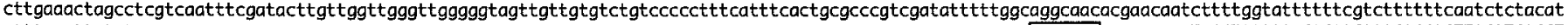

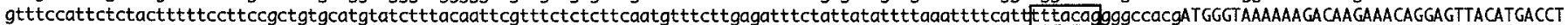

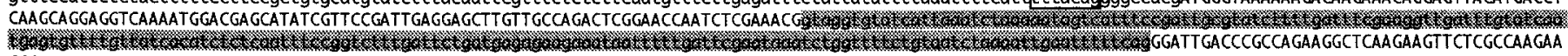
CGGACCAAATGCTTTGTCACCCCCTGAAACTACCCCAGAATGGATCAAGTTCTGTAAGAACTTGTTCGGAGGATTTGCCATGCTTCTTTGGGTTGGAGCTATCCTTTGTTACATCGCCTACTCTGTGGATATTTCACCATGGAGTACCCATCTAA GGATAACTTGTACCTCGGAATTGTACTTATGACTGTCGTCGTCATCACCGGAGTTTTCCAATACTATCAGGAAAGCAAGTCGTCGAAGATTATGGATTCCTTTAAGAACATGGTTCCAACCTTTGCTCTTGTTCACCGT GATGGCCAAAAGCAAC

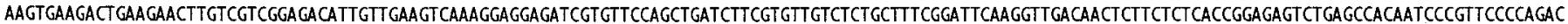

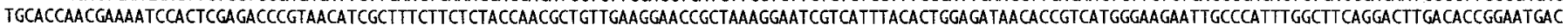

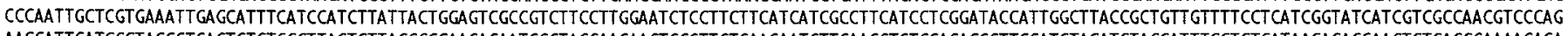

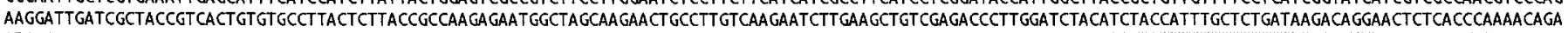

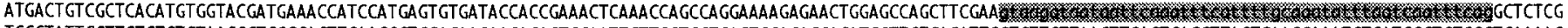

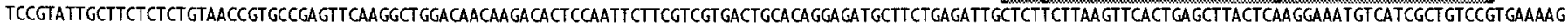

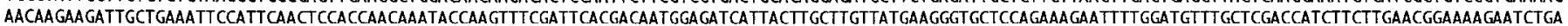

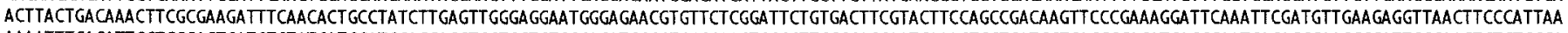

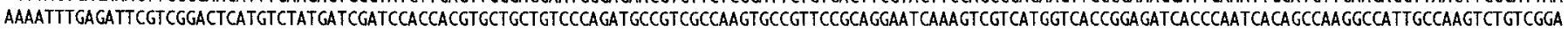

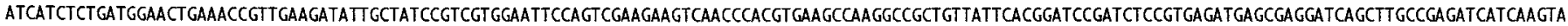

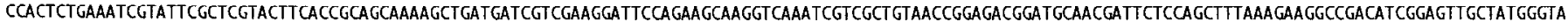

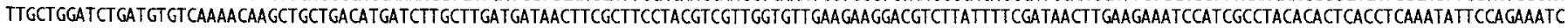

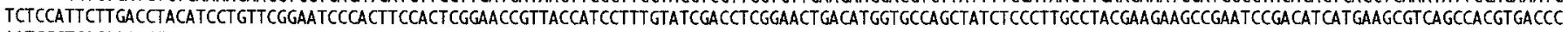

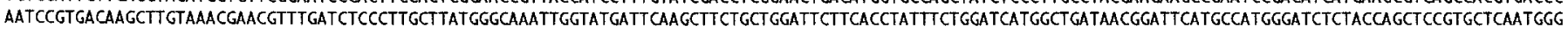
ATTCTCGTGCCTACAACAACGTTCTCGATTCCTACGGACAAGATGG

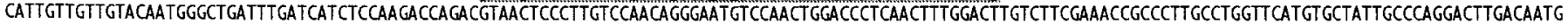

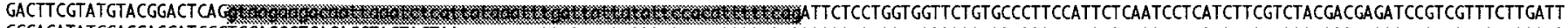

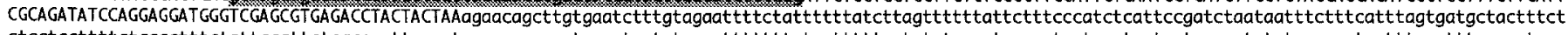

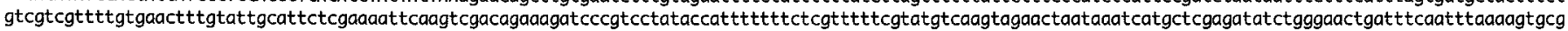

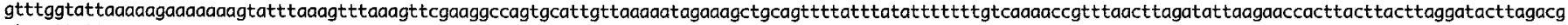
atccgttcttcaggaattc

Figure 1. Nucleotide sequence of a C. elegans Na,K-ATPase $\alpha$-subunit gene. This 5290 bp sequence begins with a HindIII site and ends at an EcoRI site. The coding sequence is shown in capital letters. A splice acceptor consensus sequence TTTACAG involved in trans-splicing of the mRNA is boxed. The four introns are highlighted.

\section{Genetic mapping and transformation rescue}

The Na,K-ATPase $\alpha$ subunit gene was mapped to the middle of chromosome $\mathrm{V}$ by analysis of restriction fragment lengths by Alan Coulson (A. Coulson, personal communication; Coulson et al., 1986). We mapped eat- 6 between the cloned gene lin-25 (Simon Tuck, personal communication) and the RFLP arP3 (Materials and Methods) on chromosome V (Fig. 3), near the clone containing the Na,K-ATPase gene. Because the eat- 6 phenotype is consistent with a defect in membrane potential, we tested the idea that eat- 6 encodes the Na,K-ATPase.

We introduced cosmid R07B8, which contains the Na,K-ATPase gene, into eat- 6 worms by germline transformation. The visible pumping defect of eat-6(ad792) was rescued in the F1 progeny of injected worms. Stably transformed lines derived from these injected worms were also tested for rescue of growth at $15^{\circ} \mathrm{C}$. After $7 \mathrm{~d}$ at $15^{\circ} \mathrm{C}$, eggs from the transformed line had grown to adult and L4 stages while all of the progeny from the parent strain were of earlier stages. eat-6(ad792) worms stably transformed with a plasmid carrying $6.2 \mathrm{~kb}$ of the genomic region around the $\mathrm{Na}, \mathrm{K}$-ATPase gene including the reported sequence plus $1 \mathrm{~kb}$ of genomic sequence at the $3^{\prime}$ end (Fig. 3) were also rescued both for pumping defects and growth at $15^{\circ} \mathrm{C}$. eat-6(ad467) worms stably transformed with this plasmid were rescued for pumping defects and electrophysiological defects (Table 1, Fig. $4 g$ ).

\section{Electropharyngeogram phenolype}

The electropharyngeogram (EPG) is a simple measure of electrical events in a C. elegars pharynx (Raizen and Avery, 1994). The EPG of a wild-type pump shows a stereotyped sequence of events that correspond to different phases of the pharyngeal muscle action potential (Fig. $4 a$ ). The excitation phase (E phase) of the action potential occurs just before the muscle contracts and is marked by positive spikes in the EPG, corresponding to muscle depolarization. The plateau phase ( $P$ phase) corresponds to the time when the muscle is contracting and sometimes contains smaller negative spikes due to inhibitory postsynaptic potentials in the muscle caused by the pharyngeal motor neuron M3 (Raizen and Avery, 1994). The repolarization phase (R phase) of the action potential occurs just before the muscle relaxes and is marked by negative spikes in the EPG, corresponding to muscle membrane potential changes in the hyperpolarizing direction. The size of EPG spikes depends on the change in pharyngeal muscle membrane potential (Raizen and Avery, 1994). Thus, a mutation that alters the EPG must directly or indirectly affect muscle membrane potentials.

EPG recordings from eat- 6 worms show a characteristic phenotype (Fig. $4 b-f$, Table 1). The E phase spikes are sometimes smaller than those of wild-type and the $\mathrm{R}$ phase spikes are much smaller or absent. These defects correlate with the motion defects of the pharyngeal muscles - a weaker contraction and a slower or delayed relaxation. Like the behavioral phenotype (Avery, 1993a), this electrophysiological phenotype is variable. For instance, while many eat-6(ad467) worms have tiny $\mathrm{R}$ phase spikes, like the worm in Figure $4 f$, others are almost normal (not shown). The $\mathrm{P}$ phase spikes of eat-6 worms appear almost normal, indicating that at least some pharyngeal nervous system function remains intact in eat-6 worms.

The R-spike sizes seen in eat- 6 mutants correlate with the decrease in growth rate and severity of starvation observed for each allele (Avery, 1993a; data not shown). This correlation also holds when cold sensitive eat-6(ad792) mutants are exposed to different temperatures. These worms have almost normal EPGs at $20^{\circ} \mathrm{C}$ (Fig. $4 c$, Table 1 ) and grow slightly slower than wildtype, but after mutant worms are placed at $15^{\circ} \mathrm{C}$ they show severely reduced $\mathrm{R}$-spikes (Fig. $4 e$, Table 1). Many mutant eggs placed at $15^{\circ} \mathrm{C}$ never grow past the LI stage. 

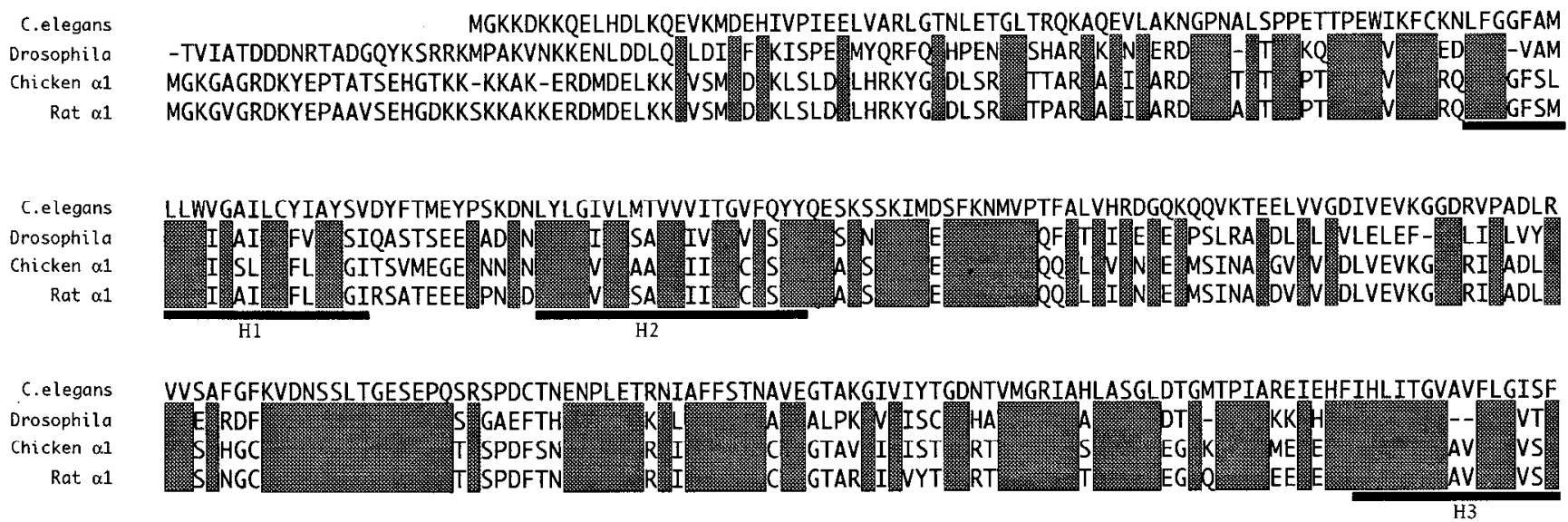

C.elegans Drosophila Chicken $\alpha 1$

Rat $\alpha 1$

C.elegans Drosophila Chicken $\alpha 1$

Rat a1

C.elegans Drosophila Chicken $\alpha \mathbf{1}$

Rat $\alpha 1$

C.elegans Drosophila Chicken $\alpha \mathbf{1}$

Rat $\alpha 1$

C.elegans Drosophila Chicken $\alpha 1$

Rat $\alpha 1$

C.elegans Drosophila Chicken $\alpha 1$

Rat $\alpha 1$

C.elegans Drosophila Chirken $\alpha 1$

Rat $\alpha 1$

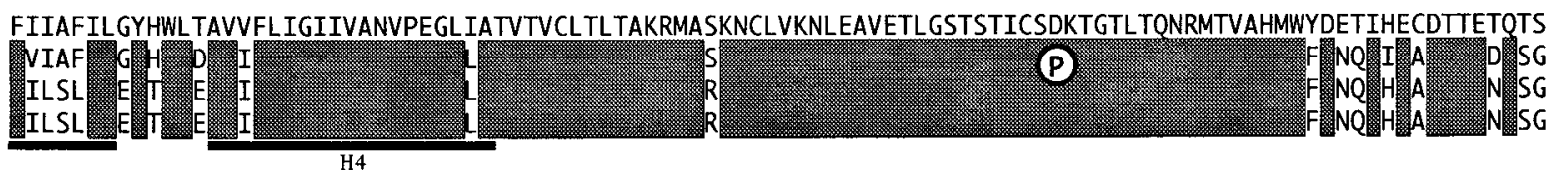

-QEKRTGASFEALVRIASLCNRAEFKAGQQDTPILRRDCTGDASEIALLKFTELTQGNVIAVREKNKKIAEIPFNSTNKYOVSIHDN----GDHYI.LVMKGA

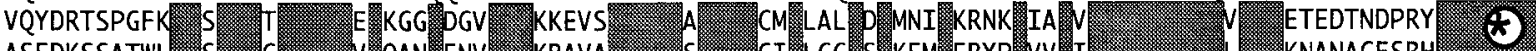

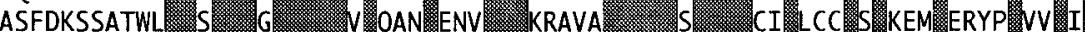
VSFDKTSATWF
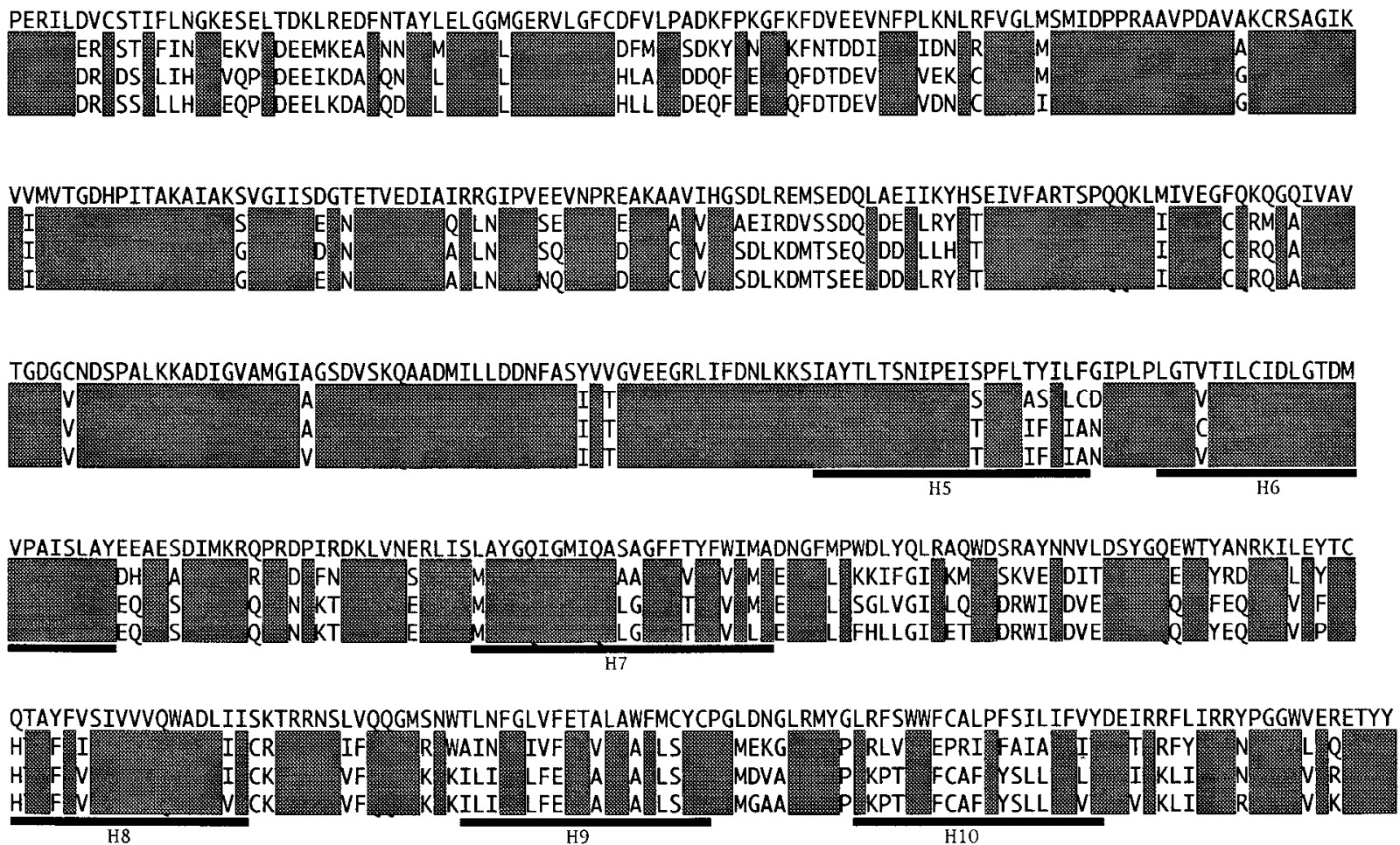

Figure 2. Amino acid sequence of the $C$. elegans Na,K-ATPase $\alpha$-subunit. The deduced amino acid sequence of the $C$. elegans Na,K-ATPase $\alpha$-subunit is shown aligned with amino acid sequences of the Drosophila melanogaster Na,K-ATPAse $\alpha$-subunit (Lebovitz et al., 1989), the chicken

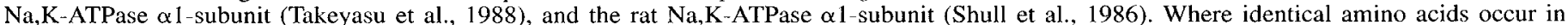
all of the Na,K-ATPase sequences, the Drosophila and vertebrate Na,K-ATPase sequences are masked. The amino-terminal region of the Drosophila $\alpha$-subunit is omitted from the figure. The 10 putative transmembrane spans $(H I-H 1 O)$ are underlined, and the phosphorylation site $(P)$ and FITCreactive site $(*)$ are indicated. 


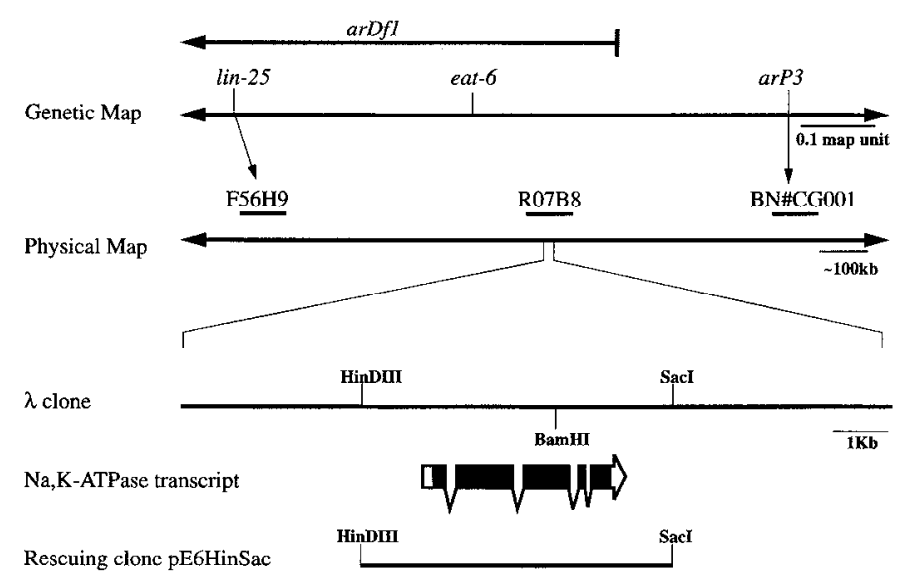

Figure 3. Genetic and physical maps around eat-6. A partial genetic map shows the approximate map distances between the cloned genetic markers flanking eat-6. The portion of the chromosome deleted in arDfI is shown by a gray bar. Arrows from the genetic loci point to associated cosmids on the physical map. Thin gray bars schematically represent portions of the cosmid contig in the region. The orientation of the partial restriction map of the lambda clone and of the Na,K-ATPase transcription unit relative to the physical map is arbitrary. The solid bars in the $\mathrm{Na}, \mathrm{K}$-ATPase transcript represent coding sequences, and open bars represent untranslated regions.

\section{Intracellular recording}

Representative intracellular recordings from wild-type and eat6(ad467) pharynxes are shown in Figure 5. Although there is variability between recordings made from different worms, recordings from eat- 6 show a resting membrane potential that is more positive and more variable than wild-type (Table 2). The action potentials in eat- 6 do not reach potentials as high as those in wild-type and are more rounded and long-lasting. The repolarization phase of the eat- 6 action potential is significantly slower and does not overshoot as far as in wild-type.

\section{The eat-6 phenotype remains when the pharyngeal nervous system is ablated}

The electrophysiological effects of eat- 6 mutations could be a direct result of loss of $\mathrm{Na}, \mathrm{K}$-ATPase function in the muscle cells, or could be an indirect effect caused by abnormal nervous system activity in the mutants. Attempting to distinguish these possibilities, we used a laser to kill 19 of the 20 pharyngeal neurons in wild-type and mutant worms, separated the pharynxes from the extrapharyngeal nervous system by dissection, and compared their phenotypes. We reasoned that if eat- 6 acted solely in the nervous system, wild-type and eat- 6 pharyngeal muscle isolated from the nervous system should behave identically. The neuron M4, necessary for efficient feeding (Avery and Horvitz, 1987), was spared to allow the worms to reach adulthood. Each of four such isolated eat-6 pharyngeal muscle preparations went into a sustained tetanus, compared to none of five isolated wildtype pharyngeal muscle preparations. This difference is significant at $P<1 \%$. To control for effects of starvation and slow growth, which were much more severe in the operated eat- 6 worms than operated wild-type, we also did the experiment on snt-1(ad596) mutant worms. snt-I encodes the synaptic vesicle protein synaptotagmin, a nervous system molecule (Nonet et al, 1993). Although operated snt- $I$ worms showed similar growth retardation and lethality to operated eat- 6 worms, none of seven isolated $s n t-l$ pharyngeal muscle preparations went into tetanus.

Although these experiments prove that eat- 6 has a site of ac- tion outside the 19 pharyngeal neurons other than M4, they leave open the possibility that eat- 6 mutations affect muscle via M4. To test this possibility, we killed M4 in wild-type and eat- 6 mutant animals. 2/12 M4- unc-29 worms (17\%) became fertile adults. In contrast, 27/35 unc-29; eat-6(ad467) worms (77\%) became fertile adults. This difference is significant at $P<0.1 \%$. Thus, eat- 6 has a site of action outside M4. The simplest explanation of eat -6 rescue of $\mathrm{M}^{-}$lethality is that eat- 6 mutation depolarizes the isthmus muscle, thereby causing it to contract in the absence of neural excitation. Consistent with this suggestion, the $\mathrm{ACh}$ agonist arecoline, which is excitatory to pharyngeal muscle (Avery and Horvitz, 1990), rescues M4- wild-type worms to the same extent $(7 / 10,70 \%)$.

We conclude that eat- 6 has a site of action in the pharynx outside the 19 pharyngeal neurons exclusive of M4, and also has a site of action outside M4. Most likely, eat-6 acts directly in the muscle cells. Our results do not argue that muscle is the sole site of eat-6 action: it may act in both neurons and muscle cells.

\section{Progeny production rates}

Unfertilized wild-type hermaphrodites produce about 300 progeny during their $4 \mathrm{~d}$ of oocyte production (Wood, 1988). Each oocyte requires a lot of material from the mother. Feeding-defective mutants produce progeny at a lower rate than normal worms, and the rate of progeny production correlates roughly with the severity of the feeding defect (unpublished observations). When the number of progeny produced by a worm during a period of time is counted, the four alleles of eat- 6 form an allelic series similar to that seen in the EPG (Fig. 6). That is, at $20^{\circ} \mathrm{C}$ the phenotype of ad601 is near wild-type, ad997 is a bit more severe and ad467 is the most severe. eat-6(ad792) showed a cold-sensitive phenotype; it was sinilar to eat-6(ad997) at $25^{\circ} \mathrm{C}$, yet was the most severely defective allele at $15^{\circ} \mathrm{C}$.

\section{Ouabain effects}

If eat- 6 mutations reduce $\mathrm{Na}, \mathrm{K}$-ATPase function in the pharynx, other treatments that reduce the function of the Na,K-ATPase in wild-type worms should mimic the eat- 6 mutant phenotype. To test this, we determined the effect of ouabain, a specific inhibitor of the Na,K-ATPase, on the function of wild-type pharynxes. $\Lambda$ pplication of $20 \mu \mathrm{M}$ ouabain to dissected pharynxes caused a large reduction in the relaxation ( $R$ phase) transients of the EPG (Fig. 7a). Although not all pharynxes are equally affected by this concentration, some of these electrical signals are very similar to those obtained from strong alleles of eat- 6 (compare Fig. $4 e, f)$. When the drug was washed out of the bath the effect was reversed, and the electrical signals returned to normal (Fig. $7 a$ ). Higher concentrations of ouabain $(35-40 \mu \mathrm{M})$ caused the muscles to hypercontract; hypercontraction also occurs in strong eat-6 mutants.

If wild-type worms have excess sodium pump capacity, low concentrations of ouabain might be expected to have little effect on them. However, a mutation in the Na,K-ATPase gene might reduce the excess sodium pump capacity and cause hypersensitivity to ouabain. To test this possibility, we measured the size of $\mathrm{R}$ phase spikes in wild-type and eat-6(ad601) in the presence of low concentrations of ouabain (Fig. $7 b$ ). ad601 is the weakest allele of eat-6, and ad601 mutants appear almost wild-type. In particular, eat-6(ad601) mutants have large R spikes, so we can clearly see any effect of ouabain on spike size. Also, because these worms have only a very weak feeding defect, secondary 


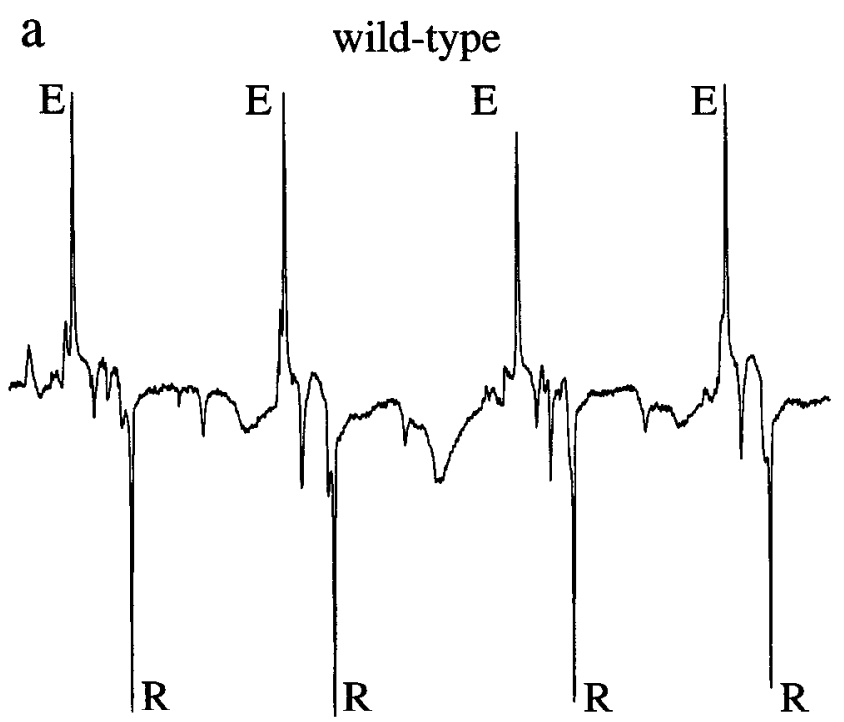

b eat-6(ad601)
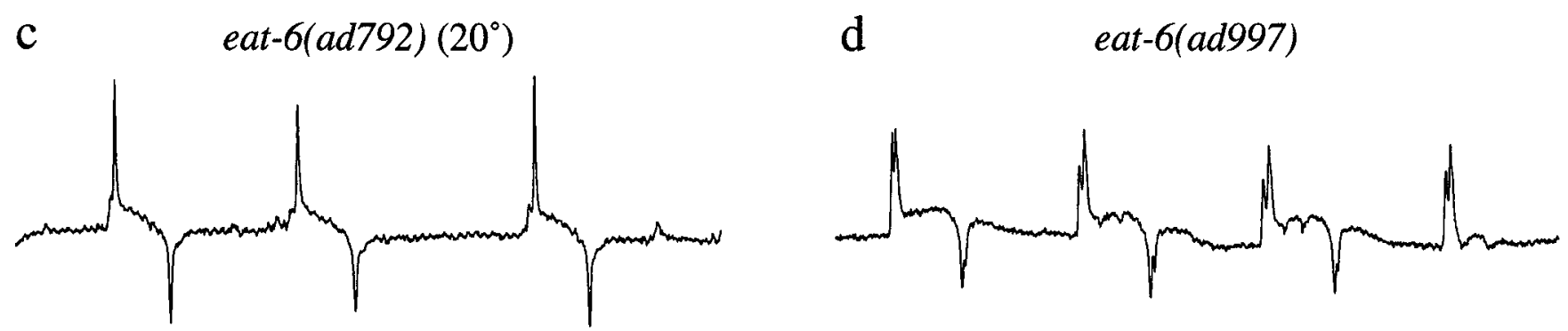

e eat-6(ad792) $\left(15^{\circ}\right)$

f eat-6(ad467)

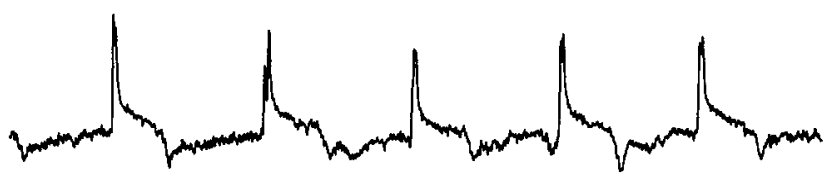

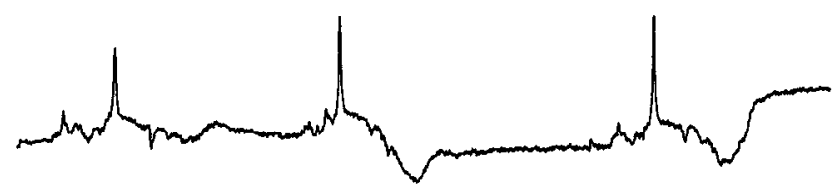
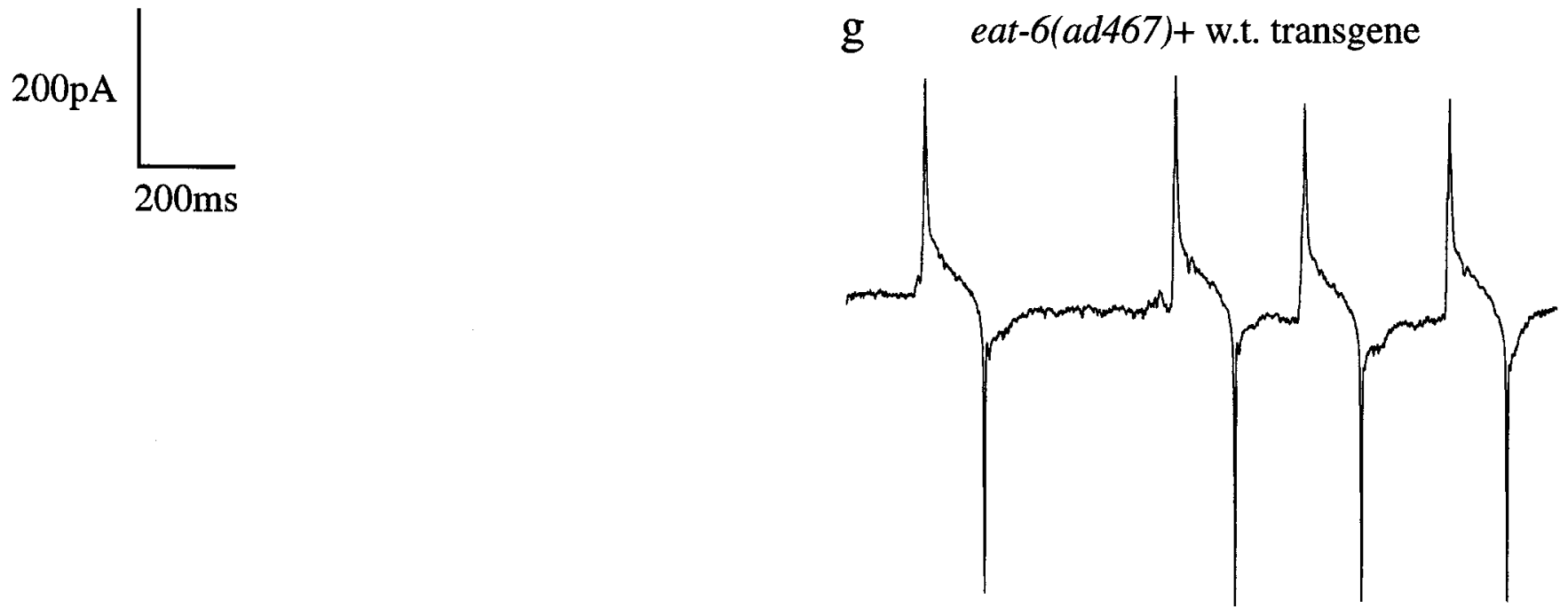

Figure 4. Electropharyngeograms of eat-6 mutants. Extracellular recordings were made from intact worms in Dent's saline +10 mM 5-HT. Relevant genotypes are indicated for each recording. $\mathrm{E}$ phase and $\mathrm{R}$ phase spikes are labeled in $(a)$. These recordings were made at ambient temperature. Except for $e$, the worms were raised at $20^{\circ} \mathrm{C}$. In $e$, the worm was raised at $20^{\circ} \mathrm{C}$ until the day before recording, then kept at $15^{\circ} \mathrm{C}$ overnight, and recordings were made after less than $10 \mathrm{~min}$ exposure to ambient temperature. 

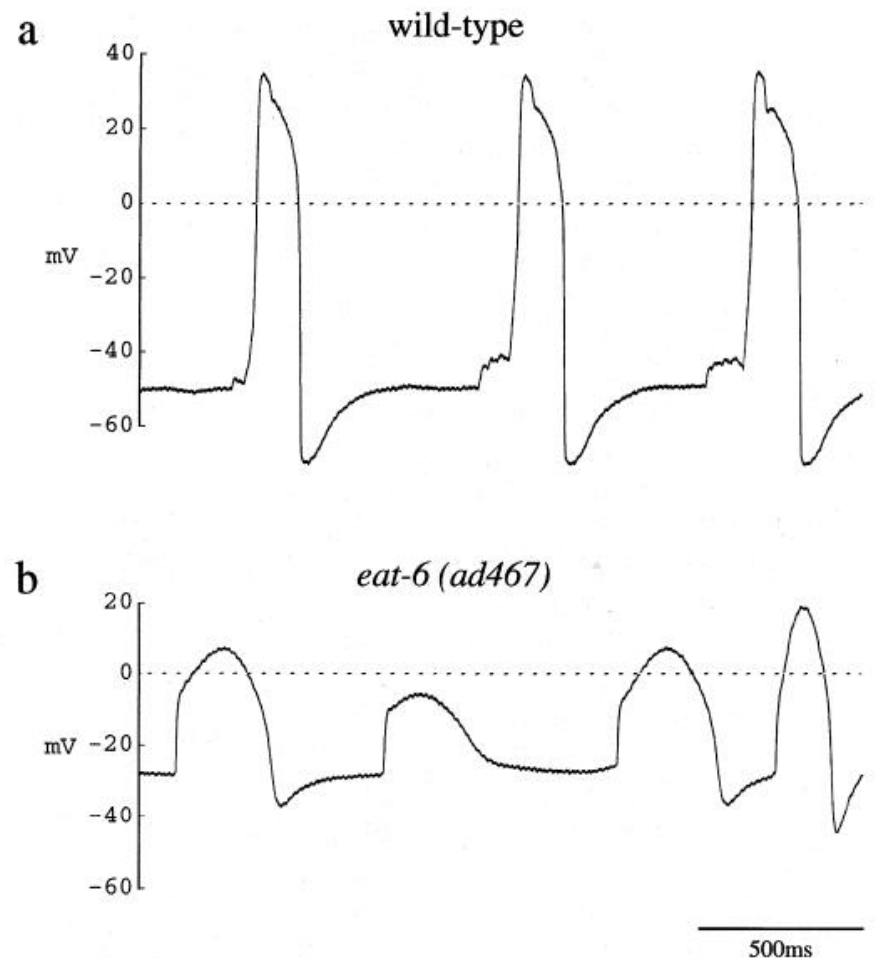

Figure 5. Intracellular recordings from wild-type and eat-6(ad467) worms. Intracellular recordings from terminal bulb muscles of dissected $a$, wild-type; and $b$, eat-6(ad467) pharynxes.

effects due to the general nutritional state of the worm are unlikely. While $10 \mu \mathrm{M}$ ouabain had little effect on the $\mathrm{R}$ spike size in wild-type worms, it greatly reduced the size of the spikes in eat-6(ad601) worms (Fig. 7 b).

These behavioral, electrical, molecular, and pharmacological phenotypes of eat- 6 are consistent with a defect in sodium pump function and support the idea that eat- 6 encodes a $C$. elegans $\mathrm{Na}, \mathrm{K}-\mathrm{ATPase}$.

\section{Discussion}

eat-6 encodes a Na,K-ATPase $\alpha$ subunit

Several lines of evidence indicate that eat- 6 encodes a $\mathrm{Na}, \mathrm{K}$ ATPase $\alpha$ subunit. First, a $6.2 \mathrm{~kb}$ genomic clone, which encodes the $\mathrm{Na}, \mathrm{K}$-ATPase $\alpha$ subunitand includes about $1 \mathrm{~kb}$ of genomic sequence $5^{\prime}$ and $3^{\prime}$ to the coding sequence rescues the mutant phenotype of eat- 6 worms. Second, eat- 6 mutant pharynxes relax slowly and have small relaxation spikes in the EPG, consistent with defects in muscle membrane potential. Further, intracellular records from eat- 6 worms show variable and reduced resting potential and abnormal action potentials, demonstrating that eat-6 mutations directly or indirectly cause defects in mus-

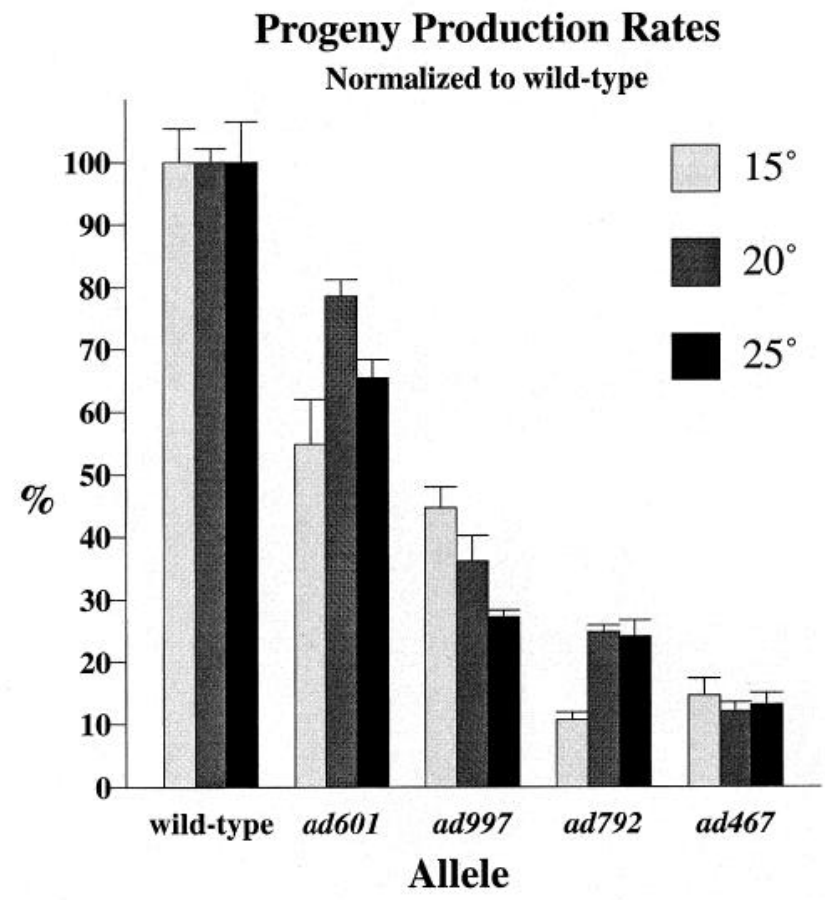

Figure 6. Progeny production rates of eat- 6 mutants. The progeny produced by three worms in $9 \mathrm{hr}$ of egg laying at the indicated temperatures were counted. Gravid adult worms of each genotype were placed at the indicated temperatures for $15 \mathrm{hr}$ prior to transferring to a fresh plate to begin egg laying. Two to five plates of three worms each were counted for each genotype. Rates were normalized to those of wild-type at the same temperature. The wild-type rates were 4.6 progeny/parent hour at $15^{\circ} \mathrm{C}, 7.9$ progeny/parent hour at $20^{\circ} \mathrm{C}$, and 8.7 progeny/ parent hour at $25^{\circ} \mathrm{C}$. The error bars indicate the normalized SEM for each measurement.

cle potentials. Third, the Na,K-ATPase inhibitor ouabain phenocopies the eat- 6 electrical phenotype, demonstrating that the eat 6 phenotype can be explained by a reduction of sodium pump function. Fourth, weak eat- 6 mutant worms are hypersensitive to ouabain, consistent with the idea that they have reduced sodium pump capacity. Schubiger et al. (1994) found similar responses to ouabain in Drosophila $\mathrm{Na}, \mathrm{K}$ ATPase mutants. They found that injections of $0.09 \mu \mathrm{l}$ of an $0.3 \mathrm{~mm}$ ouabain solution into the abdomens of adult flies phenocopied the behavioral defect seen in the Na,K ATPase mutants. They also found that this dose of ouabain, which had little effect on the viability of wildtype flies, was sufficient to kill approximately $50 \%$ of $\mathrm{Na}, \mathrm{K}$ ATPase mutant flies.

\section{eat-6 function is required throughout the life of the worm}

When eat-6(ad792) eggs were incubated at $15^{\circ} \mathrm{C}$, the hatched larvae arrested their growth at the L1 stage; these arrested L1s

Table 2. Wild-type and eat-6 intracellular recordings

\begin{tabular}{lllll} 
& $\begin{array}{l}\text { Resting membrane } \\
\text { potential } \pm \text { SEM } \\
(\mathrm{mV})\end{array}$ & $\begin{array}{l}\text { Resting } \\
\text { membrane } \\
\text { potential } \\
\text { SD }\end{array}$ & $\begin{array}{l}\text { Action potential } \\
\text { peak } \pm \text { SEM } \\
(\mathrm{mV})\end{array}$ & $\begin{array}{l}\text { Action } \\
\text { potential } \\
\text { overshoot } \pm \text { SEM } \\
(\mathrm{mV})\end{array}$ \\
\hline Wild-type $(n=7)$ & $-45 \pm 0.8$ & 2.2 & $34 \pm 3.3$ & $-67 \pm 1.5$ \\
eat-6 $($ ad467) $(n=7)$ & $-35 \pm 2.9^{*}$ & $7.6^{* * *}$ & $15 \pm 2.6^{* * *}$ & $-49 \pm 2.7^{* * * *}$
\end{tabular}

Data are wild-type and eat-6 (ad467) intracellular action-potential parameters. ${ }^{*}, P<0.05 ; * *, P<0.01 ; * * *, P$

$<0.001$ different from wild-type. 
a

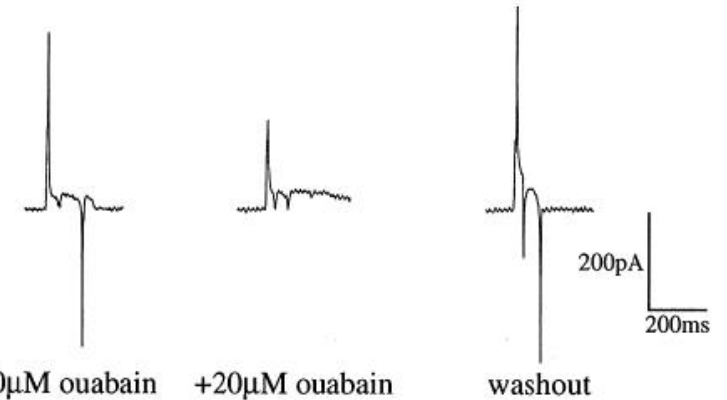

b

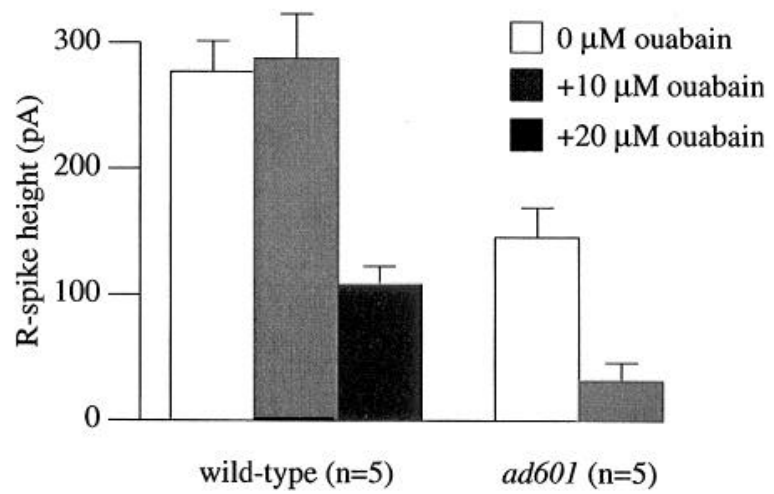

Figure 7. Ouabain phenocopy of eat-6. a, Extracellular recordings from a wild-type pharynx dissected into Dent's saline $+1 \mu \mathrm{M}$ 5-HT. Recordings were made before the addition of ouabain, 5 min after the addition of $20 \mu \mathrm{M}$ ouabain, and $5 \mathrm{~min}$ after washout of the drug. Electrical events in the presence of ouabain look similar to those recorded from severe eat-6 mutants (compare to Fig. 2a,e,f). $b$, Effects of $10 \mu \mathrm{M}$ ouabain on wild-type and eat-6(ad601). Extracellular recordings were made from wild-type and eat-6(ad601) pharynxes dissected into Dent's saline $+1 \mu \mathrm{M} 5$-HT before and after $5 \mathrm{~min}$ of exposure to $10 \mu \mathrm{M}$ ouabain. EPGs from a second set of five wild-type worms were recorded after $5 \mathrm{~min}$ of exposure to $20 \mu \mathrm{M}$ ouabain. Average R spike sizes were determined from $1 \mathrm{~min}$ of recording. The ratios of $\mathrm{R}$ spike sizes before $10 \mu \mathrm{M}$ ouabain addition to R spike sizes after $10 \mu \mathrm{M}$ ouabain addition for wild-type worms were significantly different from the ratios for eat- 6 worms $(p<1 \%)$ by the Mann-Whitney $U$ test.

resumed growth when shifted to $20^{\circ} \mathrm{C}$ (data not shown). When eat-6(ad792) worms were grown at $15^{\circ} \mathrm{C}$, and then shifted to $20^{\circ} \mathrm{C}$, electrical activity returned to near normal within $20 \mathrm{~min}$ (data not shown). These results show that the cold-sensitive phenotypes are reversible both in the L1 and in the adult, and therefore that the product of the eat- 6 gene is required at all stages rather than during a particular critical period. The rapid recovery of electrical function in the adult indicates that although the mutant sodium pump molecules cannot maintain a stable membrane potential at low temperatures, they remain able to function when the temperature rises again, probably without the synthesis of large numbers of new molecules.

\section{None of the eat- 6 alleles is likely to be null}

Usually, a null allele is expected to have the most severe phenotype of any of the recessive alleles in an allelic series. Because eat-6(ad792) worms arrest as L1 larvae at $15^{\circ} \mathrm{C}$, which is the most severe phenotype seen for any eat- 6 allele, we suspect that the null phenotype will be lethality at or before the L1 larval stage. ad792, however, is not likely to be a null allele because it can still produce functional gene product at $25^{\circ} \mathrm{C}$.

ad467 is not likely to be null because it is viable at $15^{\circ} \mathrm{C}$, which is a weaker phenotype than that of $a d 792$; however, the phenotype of ad 467 homozygotes is not noticeably different from that of worms carrying ad467 over a deficiency. This result can be explained by feedback regulation of gene expression, which has been seen for $\mathrm{Na}, \mathrm{K}$-ATPase genes in other organisms. For example, heterozygotes for a Drosophila Na,K-ATPase mutation produce almost wild-type protein levels, while homozygotes have severely reduced protein levels (Schubiger et al., 1994).

\section{eat-6 probably acts in pharyngeal muscle}

We believe the pharyngeal muscle electrophysiological defects in eat-6 mutants are the direct result of reduced sodium pump function in the muscle cells. The best evidence for a muscle site of action comes from isolation experiments in which we dissected from mutant and wild-type worms pharynxes whose nervous systems had been killed. Isolated nervous system-minus pharynxes from eat- 6 mutant worms had the characteristic eat- 6 phenotype, unlike isolated nervous system-minus pharynxes from wild-type worms. The interpretation of this experiment is independent of specific assumptions about possible effects of eat- 6 on neuronal activity. For instance, under either the hypothesis that eat- 6 mutations inactivate an inhibitory neuron or the hypothesis that eat- 6 mutations activate an excitatory neuron, wild-type and mutant would be expected to look similar after those neurons were eliminated. Although the pharyngeal motor neuron M4 was spared in these experiments, we showed separately that eat-6 has a site of action outside M4.

This argument has weaknesses. First, the pharynx contains gland cells and structural cells in addition to muscle and nervous system. However, defects in these cells cannot easily explain the muscle electrophysiological defects. Second, the isolation results are consistent with the possibility that eat-6 acts only in neurons, but that abnormal neuronal activity has an effect on muscle development, such that the muscle cells acquire abnormal electrophysiological properties that persist even after the neurons are removed. The rapid reversibility of the cold-sensitive eat6(ad792) phenotype argues against this interpretation. Finally, although we have shown that eat- 6 has a site of action outside $\mathrm{M} 4$, and that it has a site of action outside the pharyngeal neurons exclusive of M4, it is in principle possible that eat-6 acts both in M4 and one or more other pharyngeal neurons, but not in the muscle.

Although it is not incontrovertible proof, the muscle isolation experiment strongly suggests that eat- 6 electrophysiological defects are the direct result of reduction of eat- 6 function in the muscle cells themselves. Our results do not argue that muscle is the sole site of eat-6 action: it may act in both neurons and muscle cells. They do, however, argue against a model in which the abnormalities of eat- 6 mutant muscle function are an indirect consequence of loss of eat- 6 function in the nervous system. eat-6 may act in many cells, but the muscle phenotypes we have studied are a result of reduction of sodium pump function in the muscle cells themselves. This suggestion is supported by the consistency of the mutant muscle phenotype with that expected from a reduction in sodium pump function.

Although the eat- 6 mutation was isolated based on its feeding defect, eat-6 mutant worms are slightly short and fat, resembling mutants that have tonically depolarized body muscles (unpublished observations). However, eat- 6 mutants do not have any noticeable defect in locomotion or other behaviors mediated by muscles or the nervous system. This lack of other phenotypes 


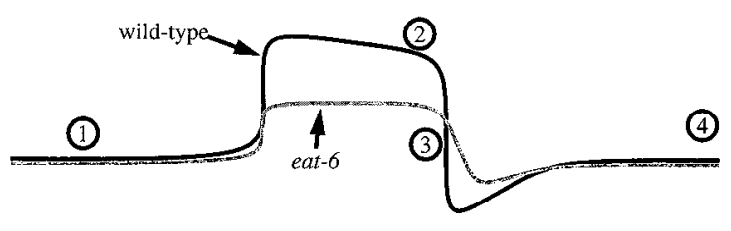

a

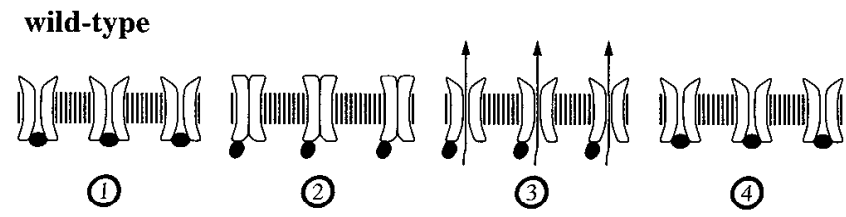

b eat-6

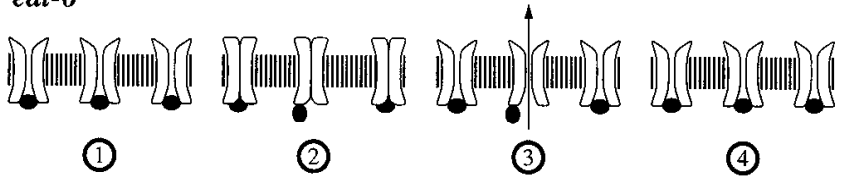

Figure 8. A model for the activation of the negative spike channel (Byerly and Masuda, 1979) during wild-type and eat-6 action potentials. $a$, In wild type, the channel is open and inactivated at rest $(1,4)$. As the muscle depolarizes (2), the channel closes and recovers from inactivation. When the potential drops below a threshold value (3), the channels open, generating a fast repolarization and overshoot before inactivating (4). $b$, In eat -6 , the action potential does not depolarize the membrane enough to remove inactivation from most of the channels. This results in a slower repolarization with a smaller overshoot.

could be explained in two ways. First, although no other genomic clones were isolated in the low stringency screen for $\mathrm{Na}, \mathrm{K}$ ATPases, it is possible that other Na,K-ATPase(s) may be preferentially expressed in tissues outside of the pharynx. A second hypothesis is that the eat- 6 gene is the only Na,K-ATPase gene in the worm, but either the pharyngeal muscles are more sensitive to changes in membrane potential than the body muscles, or the defects are more noticeable in the pharyngeal muscles, or a combination of these effects.

The effect of eat- 6 mutations on repolarization can be explained by negative spike $K^{+}$channel kinetics

The sodium pump is the engine that generates the ionic gradients on which active membrane potentials are based. Reduced pump function might be expected to reduce all potentials and potential changes, and this is indeed what we see (Fig. 7). However, there was a surprising specificity to the effects: the rate of repolarization at the end of the action potential was reduced much more than the rate of depolarization or the overall change in membrane potential (Fig. 7). This effect is especially obvious in the EPGs. Since the EPG is the timc derivative of the membrane potential (Raizen and Avery, 1993), the height of a peak reports the maximum rate of membrane potential change. eat- 6 mutations sometimes reduce the excitation peak, but the effect on the repolarization peak is more consistent and more drastic (Fig. 4). How can we explain this disproportionate effect on repolarization?

While a variety of models are possible, we favor a model based on a channel known to mediate relaxation in the pharynx of another nematode. Byerly and Masuda (1979) showed that repolarization of the pharyngeal muscles of Ascaris lumbricoides is mediated by an unusual voltage-gated $\mathrm{K}^{+}$current called the negative spike current. Its voltage dependences are essentially the reverse of those of the conventional voltage-activated
$\mathrm{Na}^{+}$conductance. It is activated by hyperpolarizing steps from depolarized potentials, is inactivated at hyperpolarized potentials, and recovers from this inactivation at depolarized potentials (Byerly and Masuda, 1979). The time constant for the recovery from inactivation is voltage-dependent, decreasing from more than $300 \mathrm{msec}$ at $-15 \mathrm{mV}$ to $30 \mathrm{msec}$ at $+10 \mathrm{mV}$ (Byerly and Masuda, 1979). The channels would be open but inactivated at rest (Fig. 8al). On depolarization, they would rapidly close, then slowly recover from inactivation during the action potential, leaving them closed but not inactivated at the end of the action potential (Fig. 8a2). At the end of the action potential a hyperpolarizing event can therefore open the channels, causing a regenerative, outward $\mathrm{K}^{+}$current to flow (Fig. 8a3). Eventually they are inactivated by the hyperpolarized potential (Fig. 8a4).

The properties of this channel can explain the slow repolarization of eat- 6 pharyngeal muscle. In the eat- 6 mutant the smaller action potential in eat- 6 pharynxes would cause these channels to recover from inactivation more slowly. Fewer channels would be available to be activated, and therefore their ability to mediate the fast repolarization seen at the end of the action potential would be reduced (Fig. $8 b$ ). The action potentials seen in Figure $5 b$ illustrate the correlation between the extent of depolarization and the speed of repolarization. The second action potential in this record has the least depolarization and the slowest repolarization of the four shown, while the last action potential has a nearly normal depolarization and a fast repolarization with a substantial overshoot.

\section{References}

Albertson DG, Thomson JN (1976) The pharynx of Caenorhabditis elegans. Philos Trans R Soc Lond [Biol] 275:299-325.

Atkinson NS, Robertson GA, Ganetzky B (1991) A component of calcium-activated potassium channels encoded by the Drosophila slo locus. Science 253:551-555.

Avery L (1993b) Motor neuron M3 controls pharyngeal muscle relaxation timing in Caenorhabditis elegans. I Exp Biol 175:283-297.

Avery L, Horvitz HR (1987) A cell that dies during wild-type C. elegans development can function as a neuron in a ced-3 mutant. Cell 51:1071-1078.

Avery L, Horvitz HR (1989) Pharyngeal pumping continues after laser killing of the pharyngeal nervous system of $C$. elegans. Neuron $3: 473-485$

Avery L, Horvitz HR (1990) Effects of starvation and neuroactive drugs on Teeding in Caenorhabditis elegans. J Exp Zool 253:263270.

Avery L (1993a) The genetics of feeding in Caenorhabditis elegans. Genetics 133:897-917.

Avery L, Lockery S, Raizen D (1995) Electrophysiological methods. In: C. elegans: modern biological analysis of an organism (Epstein HF, Shakes DC, eds), in press. New York: Academic.

Boyer HW, Roulland-Dussoix D (1969) A complementation analysis of the restriction and modification of DNA in Eschericha coli. $\mathrm{J}$ Mol Biol 41:459-472.

Brenner S (1974) The genetics of Caenorhabditis elegans. Genetics 77:71-94.

Byerly L, Masuda MO (1979) Voltage-clamp analysis of the potassium current that produces a negative-going action potential in Ascaris muscle. J Physiol (Lond) 288:263-284.

Coulson A, Sulston J, Brenner S, Karn J (1986) Toward a physical map of the genome of the nematode Caenorhabditis elegans. Proc Natl Acad Sci USA 83:7821-7825.

Delcomyn F (1974) A simple system for suction electrodes. J Electrophysiol Tech 3:22-25.

Horvitz HR, Chalfie M, Trent C, Sulston J, Evans PD (1982) Serotonin and octopamine in the nematode Caenorhabditis elegans. Science 216:1012 1014

Kramer JM, French RP, Park E-C, Johnson JJ (1990) The Caenorhab ditis elegans rol- 6 gene, which interacts with the sqt- $I$ collagen gene 
to determine organismal morphology, encodes a collagen. Mol Cell Biol 10:2081-2089.

Krause M, Hirsh D (1987) A Trans-spliced leader sequence on actin mRNA in C. elegans. Cell 49:753-761.

Lebovitz RM, Takeyasu K, Fambrough DM (1989) Molecular characterization and expression of the $\left(\mathrm{Na}^{+}, \mathrm{K}^{+}\right)$-ATPase alpha subunit in Drosophila melanogaster. EMBO J 8:193-202.

Maeda M, Ishizaki J, Futai M (1988) cDNA cloning and sequence determination of pig gastric $\left(\mathrm{H}^{+}+\mathrm{K}^{+}\right)$-ATPase. Biochem Biophys Res Commun 157:203-209.

Mello CC, Kramer JM, Stinchcomb D, Ambros V (1991) Efficient gene transfer in C. elegans: extrachromosomal maintenance and integration of transforming sequences. EMBO J 10:3959-3970.

Nonet ML, Grundahl K, Meyer BJ, Rand JB (1993) Synaptic function is impaired but not eliminated in C. elegans mutants lacking synaptotagmin. Cell 73:1291-1306.

Pavidis P, Ramaswami M, Tanouye MA (1994) The Drosophila easily shocked genc: a mutation in a phospholipid synthetic pathway causes seizure, neuronal failure, and paralysis. Cell 79:23-33.

Raizen DM, Avery L (1994) Electrical activity and behavior in the pharynx of Caenorhabditis elegans. Neuron 12:483-495.

Sanger F, Coulson AR (1975) A rapid method for determining sequences in DNA by primed synthesis with DNA polymerase. J Mol Biol 94:441-448.
Schubiger M, Feng Y, Fambrough DM, Palka J (1994) A mutation of the Drosophila sodium pump $\alpha$ subunit gene results in bang-sensitive paralysis. Neuron 12:373-381.

Shull GE, Greeb J, Lingrel JB (1986) Molecular cloning of three distinct forms of the $\mathrm{Na}^{+}, \mathrm{K}^{+}$-ATPase $\alpha$ subunit from rat brain. Biochemistry $25: 8125-8132$.

Sokal RR, Rohlf FJ (1981) Biometry. San Francisco: Freeman.

Sulston JE, Hodgkin JA (1988) Methods. In: The nematode Caenorhabditis elegans (Wood WB, ed), pp 587-606. Cold Spring Harbor, NY: Cold Spring Harbor Laboratory.

Takeyasu K, Tamkun MM, Renaud KJ, Fambrough DM (1988) Ouabain-sensitive $\left(\mathrm{Na}^{+}+\mathrm{K}^{+}\right)$-ATPase activity expressed in mouse $\mathrm{L}$ cells by transfection with DNA encoding the alpha-subunit of an avian sodium pump. J Biol Chem 263:4347-4354.

Tempel BL, Papazian DM, Schwartz TL, Jan YN, Jan LY (1987) Sequence of a probable potassium channel component encoded at Shaker locus of Drosophila. Science 237:770-775.

Warmke J, Drysdale R, Ganetzky B (1991) A distinct potassium channel polypeptide encoded by the Drosophila eag locus. Science 252: $1560-1562$.

Wood WB (1988) Introduction to C. elegans biology. In: The nematode Caenorhabditis elegans (Wood WB, ed), pp 1-17. Cold Spring Harbor, NY: Cold Spring Harbor Laboratory. 